\title{
Development Status Quo and Trend of Modern Educational Psychology
}

\author{
Huayao $\mathrm{Xu}$ \\ Handan Polytechnic College \\ Handan,056001, China
}

\begin{abstract}
When Examining the dominant ideology of educational reform movement during different time, and analyzing the interaction of Educational Psychology Development and Education Reform movement, we can see to some extent education reform enriches the theory and the content system of educational psychology, expands educational psychology research areas, enhances the awareness of the acknowledgement of education psychology, at the meantime it has the following revelation educational psychology development: teaching and learning is the basic content of the study of educational psychology; theory and practice is the foundation for the development of educational psychology; scientific thought combined with humanistic ideas is the inevitable choice of educational psychology development. Educational psychology is a science of the study of school teaching and learning activities and its operational mechanisms and basic law of interaction, although she was born less than a hundred years since the early 20th century, but it has made tremendous achievements. By systematic comparing the development of educational psychology history since its birth, this paper cites the important achievements and development characteristics of each period, and explores the hot issues currently being studied psychology, then looks into the development tendency of educational psychology.
\end{abstract}

Keywords-education reform; learning concept; teaching concept

\section{THE DEVELOPMENT HISTORY OF EDUCATIONAL} PSYCHOLOGY

History of educational psychology is educational psychology and educational psychology or psychology or pedagogy combined with each other and gradually forming an independent branch. Many Chinese and foreign history educators and thinkers have certain ideas and theories of educational psychology. 1. Confucianism as the representative idea of educational psychology contains many thought, until now it still has guiding significance and reference value. For example, thought about the learning process: quantity learning, questioning, deliberation, discernment, resourceful thinking and conducting; for the ability of teachers to understand students, inspired by induction, individualized thought; and so on. In other countries, Democritus thought learning is to develop and understand knowledge rather than the accumulation of knowledge; Plato believed that learning is born with the idea of digging out from the depths of the soul or the memories out of the process. Herbert firstly cleared psychology as the theoretical basis of pedagogy. [3] The earliest book named as educational psychology book is "Educational Psychology" published in 1877 by Russian Capjelev. Scientific psychology was born in 1879 and has greatly promoted the generation of educational psychology. Thorndike studied experimental study from 1896 and published "Educational Psychology" in 1903; we think it can mark the birth of educational psychology in the modern sense. In the 19131914 year Thorndike extends it to 3 Large, Western educational psychology system thus established, after 30 years of similar books published in the US, almost all books modeled Thorndike's system.

\section{DEVELOPMENT TREND OF EDUCATIONAL PSYCHOLOGY}

Educational Psychology Education will pay more attention to the problems in practice, and gradually expand the field of research. In addition to focus on the main two issues: teaching and learning, we believe that other issues of teaching practice will also cause concern in educational psychology. For example, the school-based issue study that Chinese scholars research is ongoing and will continue, it is possible to bring new educational psychology research, expand educational psychology research to the scope and fields, promote the development of educational psychology.

Educational psychology research methods are integrated. Because educational psychology have the characteristics of both natural sciences and social sciences, theoretical and applied scientific disciplines, coupled with her history less than a hundred years of, and therefore does not own unique educational psychology research methods. Educational psychology research often use observation, experiment, investigation, education lessons learned, case law, etc., and all borrowed from other disciplines combining the characteristics of the method of the discipline and the formation of little change. Although it largely promoted the development of educational psychology which made it achieved fruitful results in less than a hundred years and, but also hampered the development of educational psychology. Research in Educational Psychology methods should combine relevant disciplines and educational psychology research methods, combine the characteristics of the discipline, absorb the latest achievements of scientific and technological progress, form a study of educational 
psychology which really fit the integrated approach and promote the development of educational psychology.

Learning strategies, teaching strategies, problem-solving strategies, motivation, cognitive studies the interaction between the students and the learning environment is bound to further deepen or to be further strengthened.

Individual differences and individualized teaching research will continue to be taken seriously. Facing the problems caused by modern education reform, although educational psychology researchers could not fully adapt, but it can show great enthusiasm and pay close attention. "Han phenomenon" put forward the question of how to solve the contradiction of individual differences and traditional teaching problems. With the deepening of the human studies, the uniqueness of the individual get more and more attention, coupled with the development of modern educational technology, students can no longer be subject to strict time limits and space constraints of school education, and has the freedom to select the learning content and learning. This new circumstance provides a new research topic for educational psychology. The characteristics of the learning process, how to develop students' met cognitive ability and self-monitoring ability all need scientific research in educational psychology.

\section{CONTEMPORARY EDUCATIONAL PSYCHOLOGY IS HOLISTIC OBSERVATION AND META-ANALYSIS}

Holistic observation is the overall observation of actual classroom teaching activities, in order to seek the relevant of the teaching process results and student behavior. Comparing with earlier laboratory studies, it focuses on study of educational psychology which has high validity. In the overall observation, psychologists often using computer, using multiple methods analysis, cluster analysis and factor analysis for meta- factor analysis to identify effective learning success factors. Such as: in 1986 Warburg analyzed 800 kinds of factors to identify the inherent factors that affect the learning of the nine categories. At present, our psychologists are beginning to use multivariate statistical analysis techniques, but also introduced modern statistical analysis software package for the study of educational psychology adding a modern means.

Any discipline who wants a chance to survive and develop must pay close attention to social problems, especially the problem of the educational process and actively participate in the education reform movement. Our ongoing reform of primary and secondary school curriculum, educational psychology should actively participate in curriculum reform in an effort to provide theoretical guidance for curriculum reform. In addition to educational psychology can permeate throughout psychology theory of education in education reform, using the general laws of human psychological development to provide the basis for education reform, and it should also be directly involved in education reform decisions, promote the development of education reform, improving education effectiveness of reform, namely the theory of educational psychology should become a pillar of education reform practice. At present, the status and role of educational psychology in education reform is not significant, the face of modern education, education reform, educational psychology has not yet fully adapted which still need a breakthrough.

Educational Psychology is lack of localization in China. Throughout the development process of educational psychology, we learn more but less independent study. Therefore, the study of Chinese educational psychology is lack of localization. As of educational psychology content system, in addition to the psychological and aesthetic sports psychology which is not seen similar foreign textbooks, most other research comes from the West, methods and research tools also come mostly transplanted from the West. At present, China still don't have widely recognized basic theory of learning theory and teaching theory, only a few scattered studies. Therefore, as an educational psychologist, when learn from foreign countries, at the same time, we must come up with our own national characteristics theory. The combination degree of psychological theory and practical education is not high. From the perspective of educational psychology development process, there are two views of disciplinary nature: one thinks that educational psychology is the application of science. Its work focuses on the principles of psychology applied to the field of education. Another view is that educational psychology is an academic discipline which both independent and not dependent on educational psychology of particularity, the emphasis on education in the field of scientific study of psychological phenomena. This dispute between application and academic causes many problems in the combination of educational psychology theory and practice. Therefore, the theory of educational psychology researchers should work as soon as possible to the theoretical results into practical work in specific operations, guiding grassroots educators learn how to use the theory to improve teaching quality.

\section{CURRENT DeVElopMent TREND OF Chinese EDUCATIONAL PSYCHOLOGY}

Of course, our current educational psychology has great development, but due to the weak foundation liberation, liberation and twice suffered the ravages of extreme leftist thoughts, therefore comparing with better country with some basement, there are certain gap. This is reflected in that our professional team is still relatively weak, equipment and Conditions are also far less advanced countries; we are still relatively narrow scope of the study, some research system itself is not enough; for some basic theoretical issues of educational psychology itself, but is also lack of serious depth. These are contributed to our current educational psychology showing the following trends.

\section{A. Independent Development Trend}

Although the application of educational psychology emerged as a branch of psychology, but during the development lasting nearly a century, especially in recent decades, it has making educational psychology no longer simply an application of the principle of general psychology but as a relatively independent field. This independence development of educational psychology awareness is an essential point to grasp the psychology of today's educational development. In fact, the formation and development of 
educational psychology has been performing as a process, rather than a result. Early educator or educational philosopher, not only have a significant impact on the generation of educational psychology, and the work they do and the thought they made is still very important.

\section{B. Teaching and Learning is the Basic Content of Educational Psychology Study}

The initial study of educational psychology is beginning from students' study, the one-sided emphasis on learning theory research and theory was once made development of educational psychology in trouble. Starting from pragmatism education reform movement which changed the traditional teacher-centered, educational disadvantages ignore students' growth, but with a program teaching pedagogy structural failure, people come to realize the importance of teachers simply "teaching" or student the "learning" is tantamount to educational scenarios separated, one-sided emphasis will ultimately affect the results of teaching. Only fully mobilizing the enthusiasm of both teachers and students, we can promote interactive teaching and learning scenarios in order to create a good teaching environment, improve educational outcomes. So the study of teaching and learning as a whole and thus promote the development of education in various fields of psychology. Educational Psychology in its development process, although there were many branches, but teaching and learning has always occupied a central position, research, teaching and learning strategies and evaluation of teaching and learning in the progressive development of dynamic educational psychology research new areas currently.

\section{Humanistic Ideas is the Inevitable Choice of Educational Psychology Development}

Early Educational Psychology under the influence of Western mainstream psychology, trying to use accurate, objective, empirical methods of natural science to solve the education problem. Behaviorism, structuralism and cognitive psychology are the product of this philosophy. Skinner's program of teaching and curriculum reform movement Bruner thus appear once on school education have a broad impact, but because neglect of human particularity and initiative, it is difficult for students and teachers to adopt. Humanism thought in phenomenology and existentialism standing scientific basis for the educational psychology antithesis of Marxism brought a new force. Under its influence, Educational Psychology and Humanism have been developed which promote the comprehensive development of the human personality and establish a good relationship between teachers and students to make a contribution. But in the end the experience of education reform tell us too much emphasis on students 'self-selection' will lead to extreme individualism. Educational Psychology is developing into a science, to the educational process human subjects, and they should pay full attention to the discipline of their own characteristics, the use of scientific research methods and means in the cornerstone of the Humanities ongoing in-depth research to establish a scientific educational Psychology system.

\section{CONCLUSIONS}

One feature of Chinese ideological political education development is the course experiment of ideological and political education psychology. The need for ideological and political education courses of psychology is a controversial issue. Oppose course commentators have suggested that in the course of practice does not guarantee its effectiveness, which is more appropriate to solve problem within the scope of knowledge, but the psychological problems of students and other aspects of emotional behavior can not all be solved by class, the curriculum of suitable only for common problems, but difficult to solve individual problems. But the ideological and political education psychology through lectures, in the form of activities into the classroom curriculum, has proven to be a very good attempt. Meanwhile, for our students, less ideological and political education psychology teacher characteristics, the prevalence of many mental healths of students through lectures, activities, programs to solve. Decades, the development of educational psychology has experienced brought in, repeat the validation to absorb learning, in-depth exploration of innovation and development until the actual process. Especially with Chinese education reform in certain areas of research remarkable, these can be said contribute to the development of education to make the world of psychology. But the case of research areas, aspects is not wide and a variety of internal subject and external factors affecting educational object comprehensive application to its research methods and multivariate analysis, and theoretical summary of research results and summarize our traditional thinking of educational psychology mining to form a faction with Chinese characteristics, educational psychology and theories are all to be strengthened. Especially facing a number of issues raised by the education which actual need for more indepth study.

\section{References}

[1] Zhang Wen, Zhang Dajun. From the West to See the Development of Modern Education Reform Movement in Educational Psychology. [J] Contemporary Education Forum (macroscopic Education Research), 2007, 02: 49-51.

[2] Gao Hongyan, Wang Yungui. Development Status and Trends of Modern Educational Psychology [J] Northwest Medical Education, 2005,03: 285-286.

[3] Cheng Gang, Zeng Jieying. Development and Prospect of Educational Psychology [J] Psychological Science, 1995, 04: 247-249.

[4] Song Hua. On the development process of China Educational Psychology [J] Neijiang Technology, 2011, 04: $81+116$.

[5] Zhang Li Juan, Song Mingling. Challenge for the Development of Community Educational Psychology Development [J] Psychology theory, 2012, 35: 67-68.

[6] Wang Xiaoxin. History and Trend of Development of New Educational Psychology [J] Liaoning Normal University, 2002, 05: 49-51. 